\title{
Geographies of Mobility: A Brief Introduction
}

\author{
Simon Cook \\ Department of Geography, Royal Holloway University of London \\ Faculty of Health, Education and Life Sciences, Birmingham City University \\ Simon.Cook.2013@live.rhul.ac.uk \\ Simon.Cook@bcu.ac.uk
}

\begin{abstract}
This article introduces readers to the concept of mobility and some recent ways in which it has been approached in geography. In doing so, it aims to encourage a meaningful engagement with the ideas and issues of mobility as well as an appreciation of the breadth of mobilities research. As such, this article demonstrates the centrality of movement and mobility to, not only, the discipline of geography but also to some of society's most pressing challenges and to the mundane happenings of everyday life. This article begins by demonstrating this centrality of movement to contemporary life, before charting the conceptual development of the mobilities turn, and the need to understand mobility as relational. Relatable examples are used throughout to show mobilities in action and highlight the significance of ideas and issues of mobility for contemporary geography.
\end{abstract}

\section{Introduction}

Geography is moving. In fact, "the entire world seems to be on the move" (Sheller and Urry, 2006: p.207) and over the last two decades, an influential body of work has developed within geography interested in understanding this movement, the importance of mobility, and in developing our understanding of mobility. The impact of this work has been significant enough that it has established mobility as a key idea in human geography. Mobility is now considered a fundamental concept of the discipline, alongside those which may more readily come to mind, such as space and place (Cresswell, 2008a). Consequently, it is now more vital than ever for students of geography to understand and engage with mobility.

All corners of human geography have been animated by issues of movement and mobility and studying geography without being confronted with issues of mobility would be very difficult, if not impossible. It is the intention of this paper therefore to introduce readers to some of the ways in which mobility has been approached, researched and understood within geography. In doing so, I hope to provide a solid grounding in one of the discipline's key concepts. This begins by demonstrating the centrality of movement to how we live our lives, and the ways it both underpins and intertwines with some of the geographical processes which make up life on earth. This is followed by a discussion of how mobility as a geographical concept has evolved and the mobile turn which has accompanied it. After which I highlight the crucial relational nature of mobility to further demonstrate the significance of ideas and issues of mobility for contemporary geography and contemporary life.

\section{Movement everywhere}

Movement is an inescapable and fundamental fact of life - it underpins the extraordinary and the everyday. Its intricate and never-ending links with geography are something we take for granted each day. Often, only when mobility is disrupted do we stop to consider our perpetual motion. Spending 
just a minute, trying to peel away that taken-for-grantedness can reveal some of the complex, remarkable and challenging ways in which our lives are entangled with mobility.

Think about what has happened so far today to get you here. What forms of movement have you experienced and encountered that have enabled you to be reading this paper right now? Make a list and write it down if you like. Here is my attempt:

I am currently writing this on a train travelling the 120 or so miles from Birmingham Snow Hill Station to London Marylebone Station. As these words are being typed, I am somewhere in the North Oxfordshire countryside, sharing the carriage with long-distance commuters, weekend-away travellers, and shoppers heading to Bicester Village - a shopping outlet centre stocking products resourced, made, and marketed all over the world, and distributed by ship, plane and vehicles. I am utilising the time to get some work done. I connect to the train's Wi-Fi in order to send an email, an act which transmits data from my laptop via my email provider's server in Blueridge, Virginia, to my recipient's email provider's server, and finally to my recipient's laptop, back in Birmingham.

The email is a reply to my colleague, who asked if I made the train. Public transport connections between these areas my university and the train station are not great so l opted to use my scooter (an adult-sized one) to cover the distance quickly. Unlike a bike, my scooter can fold up and be stored easily on the train. My scooter is of Swiss design but powered by me. The blood, oxygen, and electric signals that course around my body allow my limbs to move and propel me forward. I arrive slightly ahead of time so take the opportunity to nip to the toilet. Doing so, requires even more movement. There are internal bodily movements (I will let you use your imagination), the movement of clean water into the building, which ultimately helps to move the sewage out. Movements of water and air follow as I wash and dry my hands.

I am taking this train at the end of first week at Birmingham City University. For the time being however, I still live in London where I have been based for the last four years. This journey is a migration, an internal economic migration that I will make at either end of the week. This is complicated a little, however, as this journey is also a homecoming. While living in London, I am from Solihull, a town bordering Birmingham on its south-east edge. During the week, I am living with my mum and this makes me part of the so called 'Boomerang Generation'. I am a millennial who left home for educational and economic reasons, moved to a different place and experienced living independently, only to return to my family home once again. I have been away for seven years and soon will be living full-time back with parents. The current high cost of renting and poor prospects of home-owning in London made it financially impossible to stay in London long-term. These are conditions created by the coming together of a huge array of factors: foreign investment in the London housing market and the distribution of graduate-level jobs in the UK are just two examples. These flows of people and capital into London are consequently fuelling the high demand for housing and the subsequent inflation of prices.

My Friday night train from Birmingham to London is part of these multiple mobilities.

As you can see, just analysing one seemingly simple journey from Birmingham to London reveals a vast array of movements and mobilities with which it is entangled. These are mobilities close by and far away; present day, historic and of the future; spanning the smallest and largest scales; of different durations, of different frequencies, and differing rhythms. They are concerned with the movements of people, things, data, ideas; and movements relating to a whole host of different processes, from education, employment, leisure and health to international trade, telecommunications, sanitation and bodily functioning. Go back and look at the list you made. What different scales, processes and types of movement have you encountered? 
This example demonstrates the centrality of movement to contemporary life. Simply, mobility is everywhere and is an essential component of life. It is, however, only recently that geographers have thought more conceptually about mobility and the following section explores some of this thinking.

\section{The mobile turn}

Despite the above statement, it would not be fair or correct to claim that geography has only just discovered mobility. In fact, geography has a very long history of researching all forms of movement, some of which I am sure you have already studied over the course of your geography education. Consider the work you may have already done around migration, rivers, tourism, transport, coasts, urban settlements, glaciers and trade. Movement is at the heart of all these topics and they have all been long studied within geography.

This said, it would be fair to claim that the nature and intensity of more recent engagements with mobility in geography are indeed different to these more longstanding interests in movement. The past two decades have witnessed mobility studies expand considerably as a scholarly field, with academics from disciplines across the social sciences, arts and humanities becoming enthused by issues of movement and orientating their work to attend to the questions posed by the developing understandings of mobility. This growing orientation has been termed the mobile turn (Cresswell, 2011).

While it is easy to overstate the differences with earlier work, there are perhaps three key attributes, which sets more recent mobility work apart from previous geographical work on movement. Firstly, is the perception that movement is a centrally important geographical agent in its own right something which is productive of places, social relations and phenomena. Prior to this, the dominant thought within geography considered mobility as somehow in-between places, as merely producing geographies elsewhere, devoid of its own effects (Crang, 2002). The growing recognition of the importance of mobility, however, altered this perception and ushered in a more conceptual approach to the study of mobility within geography. Mobility is now seen as a vital component in theories about space, place, and the human world (Massey, 2005), and lies "at the center of constellations of power, the creation of identities and the microgeographies of everyday life" (Cresswell, 2011: p.551). The growing recognition of mobility has also challenged geographers to think about the nature of mobility itself and to attempt to theorise it (more on that below).

The second key attribute which distinguishes current geographical work on mobility is an expanding and intensifying engagement with it. This is, in part, a response to these newer conceptual approaches to mobility, as well as a response to the perceived increasing mobility of the contemporary world. For example, in the 54 years from 1952 to 2016 the United Kingdom has witnessed a 1000\% increase in passenger kilometres travelled by car, van and taxi. In 2016, these totalled 668,000,000,000 kilometres (Department for Transport, 2017). Similarly, the number of people arriving and departing the United Kingdom by air has almost tripled since 1991, standing at 268 million passengers in 2016 (Department for Transport, 2017). Correspondingly, the practices, spaces and subjects of mobility are being studied by geographers more broadly and intensely than ever before. There are now studies exploring all sorts of mobilities, from those human powered, such as walking (Middleton, 2010), running (Cook et al, 2016a) and cycling (Spinney, 2009); to those mechanically powered, such as trains (Bissell, 2009), cars (Merriman, 2009) and aeroplanes (Lin, 2015); to the mobilities of data (Kitchin and Dodge, 2011), animals (Law, 2006), warfare (Merriman et al, 2017) disease (Lavau, 2014), products (Cook, 2004), ideas (Temenos and McCann, 2013) and more (see Adey et al, 2014).

John Urry (2007) developed a notable typology to make sense of the wide variety of mobilities being studied. He argued that five different types of mobilities underpin the processes of contemporary societies and, to some extent, all mobility studies relate to one of the following: 
- The movement of people (corporeal mobility)

- The physical movement of objects

- Imaginative travel (such as via the television)

- Virtual travel (such as through the Internet)

- Communicative travel (such as telephone conversations)

The third key attribute which distinguishes current geographical work on mobility is a methodological one. The increased attention to mobility has been met by a similar proliferation in methods which seek to move with the subjects they are studying. These have become known as mobile methods aiming to variously trace, track, keep up with and move-along with the phenomena being researched. This is a development based on the argument that spatial and temporal proximity brings methodological value to a study (Cook et al, 2016b) and that traditional methods somehow deal poorly with the nature of mobile phenomena. Although the necessity of these method are still being debated (Merriman, 2014), it has not stalled their expansion. Mobile video ethnography (Spinney, 2011; Simpson, 2014), go-along interviews (Anderson, 2004; Finlay and Bowman, 2017), mobile ethnography (Kusenbach, 2003; Novoa, 2015), GPS tracking (Bell et al, 2015; Merchant, 2017), photo-elicitation (Middleton, 2010), phone-tracking (Taylor, 2016) and autoethnography (Larsen, 2014) among others have all become tools more frequently incorporated into the geographer's toolkit over recent years. Such methods represent a big difference in how mobilities had previously been researched and an innovation in how we might understand mobility. For more on mobile methods see Ricketts-Hein et al (2008), Watts and Urry (2008), Büscher and Urry (2009), Büscher et al (2011), D'Andrea et al (2011), Fincham et al (2011), Harada and Waitt (2013), Merriman (2014), Murry and Upstone (2014), and Spinney (2015).

The mobile turn is now well-established and has spawned at least three academic journals dedicated to mobilities research (Mobilities, Applied Mobilities, and Transfers), one interdisciplinary handbook (Adey et al, 2014), two geographical textbooks (Adey, 2017; Cresswell and Merriman, 2011), multiple research organisations/centres all over the world, and a wealth of review articles (these are great for grasping the breadth and depth of mobilities research, see Cresswell, 2011; 2012; 2014; Merriman, 2015; 2016; 2017; Hannam et al, 2006; Sheller and Urry, 2006; 2016; Sheller, 2011; 2017; Falconbridge and Hui, 2016; Vannini, 2010; Kwan and Schwanen, 2016). But alongside this institutional imprint, the mobile turn has had a marked impact beyond academia, as the understandings of mobilities research are being adopted and implemented by governments, policy makers, planners, and other stakeholders/practitioners. Mobilities research is being applied to and helping to improve things in the 'real world' too.

\section{Movement and mobility}

So far, I have used mobility interchangeably with the word movement, but actually it is the key conceptual distinction between these two terms which marks an important foundation of mobilities research.

The geographer Tim Cresswell sought to explain this analytical distinction throughout a series of influential works $(2001 ; 2006 ; 2010)$. He asks us to imagine a line, connecting Point A with Point B. This line represents a journey from one place to another. Understanding this line with an interest in movement is explained by accounts of the relative merits of departure and arrival points, the pushpull factors (Spinney, 2009), and perhaps some basic information about that connecting line, such as distance, duration, route, speed etc. In this way, movement is seen as a function in abstract space. It seeks to tell us about the simple getting from Point A to Point B and little about the actual movement itself: little about how that line was experienced, about what politics produced that line, about what power relations shaped that experience, and about the ways in which that journey was meaningful. As an analytical concept, movement is devoid of meaning, history, ideology or social, cultural and 
political context associated with the line connecting Point A and Point B. Movement is simply an act of displacement that allows things to get from one location to another - a measurable and mappable phenomenon.

Mobility, on the other hand, understands that moving between $A$ and $B$ is rarely ever just movement. Rather it is something viewed as being deeply imbued with meaning. Mobility is interested in bringing that line to life and in revealing the textures and contexts of that journey. It asks how movement is lived, is felt, is meaningful, is political, is powerful, what affects it, and what its effects are. As an analytical concept, mobility is anything but abstract, it is a meaningful and power-laden phenomenon full of social, cultural and political context.

An example might be useful to illustrate this difference. Imagine you are in a car on the way to college or university with friends. If we were to analyse this through the lens of movement, we may want to consider the push-pull factors involved in this journey. Here, education is motivating the journey to take place. We may also analyse the departure and arrival locations (so your house and college/university), the route taken, the people undertaking the journey, the distance, the speed at which it was done, and the time of day the journey took place. We may then want to compare these to other movement patterns to understand how this journey fits in with the wider transport flows. This is understanding movement abstractly.

While these attributes would still be of interest if we were to analyse this journey through the lens of mobility, we would also seek to understand the wider context of the journey and the ways in which it was meaningful. For example, we may understand automobility (the practice of car-driving) as freedom. A freedom to go where we want to, when we want to. A freedom to be in control of our own movement, no longer reliant on parents or public transport. In this journey, the car itself doubles-up as a space for socialisation, providing an alternative space for hanging out (Merriman, 2009). These beyond-abstract functions of driving often lead us to developing strong attachment to our cars. They become our spaces, places where we feel safe, where we belong, and which represent us to the wider world (Lumsden, 2013). They are also spaces of experience and emotion. For some, driving is a thrilling and exhilarating experience. The sense of speed, the vibrations of the engine and the noise of the machinery all combine to produce an intoxicating experience. For others, driving can be anxietyproducing event - an experience riddled with nerves, fear and stress.

The insights that 'movement' and 'mobility' perspectives offer into understanding this journey are both important and interesting, they simply tell us different things about it. Proponents of mobility argue the insights into the meanings and experiences of mobility are essential for understanding any mobility - automobility in our case. They help us understand why and how we drive our cars, how we become attached to them, and how we may be able to intervene to create more sustainable transport systems. It is not the case that any of these approaches are better in understanding the mobile world, they simply ask different questions of it and approach it from different perspectives. Indeed, many mobility scholars recognise a continuum between the movement and mobility perspectives and seek to work across this (Shaw and Hesse, 2010; Shaw and Sidaway, 2011). This is possibly best conceptualised in Tim Cresswell's theorisation of human mobility, which we will look at now.

\section{Holistic Mobility - A Geographical Approach to Human Mobility}

Tim Cresswell $(2001 ; 2006 ; 2010)$ developed an analytical framework which brings various traditions of studying mobility together in a more holistic approach. This has become influential within geography and applied to a huge range of human mobilities, from the mundane movement of daily joggers (Cook et al, 2016c) to the life-affecting evacuation mobilities following Hurricane Katrina (Cresswell, 2008b). This approach rests on thinking about mobilities as produced. 
Cresswell proposes that the production of holistic mobility consists of the interweaving of three aspects of mobility - movement, representation and experience. Each aspect represents a different way of approaching mobility, the combination of which results in deeper connected understandings of mobile practices. Here, movement concerns the brute facts of getting from one place to another and are the raw material for the production of mobilities. It is interested in who moved, how they moved, where they moved, how quickly they moved and so on. Representation is concerned with the meanings given to mobility and how they become meaningful. These meanings can be individually held or shared and found in sources ranging from policy, TV, radio, adverts, books, art and more. They demonstrate that mobility is, at least partially, produced by the way we talk about them. Finally, experience attends to the fact that human mobility is a practiced mobility - it is something enacted, embodied and lived. Experience is interested in how mobility actually happens, what it feels like to do it, what emotions it conjures up, how it involves our bodies and the interactions we have with others.

This framework works across the movement-mobility continuum by entwining various approaches to the study of movement and can offer previously unknown insights, connections and understandings about mobility. Indeed, as Shaw and Docherty (2014: p.32) argue, the getting "from anywhere to anywhere in any circumstances is likely to be most insightful and accomplished if it is grounded in a good understanding of all three of Cresswell's triumvirate of movement, experience and representation".

\section{Relational Mobility}

Finally, in our brief tour of mobility geographies, we turn to considering how movement is political, powerful and meaningful as a geographical agent by considering it as relational. The increasing engagement with mobility over recent decades could lead to seeing everything as mobile. To some extent, everything is moving. Even something that seems static, like a building, is teeming with movement. Flows of people, objects, water, electricity, and data continually move in and out of it, and the building itself is designed to give and sway with the elements, as well as being constantly eroded, albeit on a very slow timescale. Yet, understanding everything as mobile in this way, ultimately diminishes the analytical power of mobility. As Peter Adey (2006) argues, if mobility is everything then it is nothing. Therefore, we must understand how mobility is relational and this idea has emerged at the heart of mobility research.

By relational, we mean that mobility is a relation. It connects things together in ways which serve to unite and link as well as differentiate and discriminate. Mobility can bring places closer together as well as make others seem further apart, it can bring some people together while separating others, as well as helping to communicate meanings, significance, power and ideas. Consider a trip by aeroplane from Johannesburg to London. Two places 5635 miles apart, brought closer together through flight what was once $10+$ days by boat, is now only 11 hours 20 minutes by plane for those who can afford it. Meanwhile, Oshataki, Namibia now feels relatively further away as it is not possible to fly there from Johannesburg. Despite being 4435 miles closer, it is 10 hours further away than London to travel to from Johannesburg. The flight itself may function to connect families and friends, both during the flight and on arrival, yet it also serves to separate. Communities surrounding the airports in London and Johannesburg find themselves cleaved apart by an impenetrable airport city; passengers on the flight are segregated by class and ability to pay; they are also separated from those for who an aeroplane is a site of work; and from any stowaways in the hold, risking death in the hopes of a better life. This demonstrates that, along with passengers and cargo, this flights also transports meanings, ideas and power too.

Though important in creating relations between people and places, it is important to remember that mobility is also a relation itself. Mobility is a valuable resource in society, but one that is accessed and experienced differently. A thing's ability to move, how it moves, the speed at which it moves, the ease 
of that movement and the experience of that movement all provide insights into that thing's status in society. As a simple example, consider the different connotations attached to travel by bus and private jet. One is often nicknamed the 'loser cruiser' and is associated with slow, uncomfortable but cheap travel over relatively shorter distances, for which you must frequently wait. The other offers almost seamless global travel with luxurious comfort, unparalleled speed, ultimate flexibility and is associated with the rich and famous (Spence, 2014). These modes of mobility highlight the varying accesses to, ease of and experiences of mobility which make it function as social relation and work to differentiate in society.

In these ways (and many more) mobility is an important geographical relation and agent, one productive of power, places, peoples, justices, injustices and connections. Mobility is much more than an abstract functioning, it is inherently political in the ways it permits, restricts and differentiates people's mobility and mobile experiences. These are ideas developed further in Doreen Massey's notion of power geometries (1993) and Tim Cresswell's politics of mobility (2010). Ultimately, it is crucial to consider mobility as in relation and linked to everything else. Any movement, or lack of it, has wide-ranging effects and is affected by a huge variety of things. Therefore, we should always consider mobility, not in isolation, but in relation-to someone or something else (Adey, 2017).

\section{Conclusion}

This short article has offered a concise yet critical introduction to a major concept within geography, that of mobility. Throughout your geographical studies, it is inevitable that you will come across issues of mobility and this article has demonstrated the centrality of that movement to geography, to social and spatial theories, and to the processes of contemporary life. This recognition has led, over the last two decades, to an increasing theorisation of and attention to mobility, grounded upon the notion of mobility as a meaningful, lived and contextualised phenomenon, productive of places, people and politics. Along with the emergence of mobile methods, these aspects of mobility studies demarcate it from longer traditions of studying movement within geography but this is also a difference easy to overstate. Therefore, the idea of a movement-mobility continuum was introduced, along with Tim Cresswell's production of mobilities as one approach which seeks to work across this continuum. Finally, the idea of mobility as relational was proposed, which seeks to understand mobility as always in-relation to someone or something else, and in doing so, helping to connect/differentiate people and places and ultimately leads to an appreciation of the power and politics bound up in mobility and immobility.

This all demonstrates the importance of mobility for the contemporary world, and for geographers. The development of mobility geographies has been sustained and wide-ranging with mobility now considered as one of the fundamental concepts of the discipline. This article has introduced readers to the underlying ideas of mobility studies, the key questions it seeks to ask, and the nature of the mobilities research. It is only intended as a brief introduction however and is far from detailed. Rather this paper serves as a signpost to some of the big ideas and thinkers involved with mobilities and should be used a springboard to explore further and to follow your curiosity. The references below are a very good place to start. 


\section{References}

Adey, P. (2006) 'If Mobility is Everything Then it is Nothing: Towards a Relational Politics of (Im)mobilities' Mobilities, 1(1): pp.75-94.

Adey, P. (2017) Mobility, Second Edition, Routledge, Abingdon.

Adey, P., Bissell, D., Hannam, K., Merriman, P. and Sheller, M. (eds) (2014) The Routledge Handbook of Mobilities, Routledge, Abingdon.

Anderson, J. (2004) 'Talking whilst walking: a geographical archaeology of knowledge' Area, 36(3): pp.254-261

Bell, S.L., Phoenix, C., Lovell, R. and Wheeler, B.W. (2015) 'Using GPS and geo-narratives: a methodological approach for understanding and situating everyday green space encounters' Area, 47(1): pp.88-96.

Bissell, D. (2009) 'Conceptualising differently-mobile passengers: geographies of everyday encumbrance in the railway station' Social \& Cultural Geography, 10(2): pp.173-195.

Büscher, M. and Urry, J. (2009) 'Mobile Methods and the Empirical' European Journal of Social Theory, 12(1): pp.99-116.

Büscher, M., Urry, J. and Witchger, K. (eds) (2010) Mobile Methods, Routledge, Abingdon.

Cook, I. (2004) 'Follow the Thing: Papaya' Antipode, 36(4): pp.642-664.

Cook, S., Shaw, J. and Simpson, P. (2016a) 'Running Order: Urban Public Space, Everyday Citizenship and Sporting Subjectivities' in: Koch, N. (ed.) Critical Geographies of Sport: Space, Power and Sport in Global Perspective, Routledge, Abingdon: pp.157-172.

Cook, S., Davidson, A., Stratford, E., Middleton, J., Plyushteva, A., Fitt, H., Cranston, S., Simpson, P., Delaney, H., Evans, K., Jones, A., Kershaw, J., Williams, N., Bissell, D., Duncan, T., Sengers, F., Elvy, J., and Wilmott, C. (2016b) 'Co-Producing Mobilities: negotiating geographical knowledge in a conference session on the move' Journal of Geography in Higher Education, 40 (3): pp.340-374.

Cook, S., Shaw, J., and Simpson, P. (2016c) 'Jography: Exploring Meanings, Experiences and Spatialities of Recreational Road-running' Mobilities, 11(5): pp.744-769.

Crang, M. (2002) 'Between places: producing hubs, flows, and networks' Environment and Planning A, 3(4): pp. 4569-4574.

Cresswell, T. (2001) 'The Production of Mobilities' New Formations, 43: pp.11-25.

Cresswell, T. (2008a) 'Place: encountering geography as philosophy’ Geography, 93(3): pp.132-139.

Cresswell, T. (2008b) ‘Understanding Mobility Holistically: The Case of Hurricane Katrina' in: Bergmann, S. and Sager, T. (eds) The Ethics of Mobilities: Rethinking Place, Exclusion, Freedom and Environment, Ashgate, Aldershot: pp. 129 - 140.

Cresswell, T. (2010) 'Towards a politics of mobility' Environment and Planning D: Society and Space, 28(1): pp.17-31.

Cresswell, T. (2011) 'Mobilities I: Catching up' Progress in Human Geography, 35(4): pp.550-558.

Cresswell, T. (2012)’Mobilities II: Still' Progress in Human Geography, 36(5): pp.645-653. 
Cresswell, T. (2014) 'Mobilities III: Moving on' Progress in Human Geography, 38(5), 712-721.

Cresswell, T. and Merriman, P. (2011) Geographies of Mobilities: Practices, Spaces, Subjects, Ashgate, Aldershot.

D'Andrea, A., Ciolfi, L. and Gray, B. (2011) 'Methodological Challenges and Innovations in Mobilities Research' Mobilities, 6(2): pp.149-160.

Department for Transport (2017) Transport Statistics Great Britain 2017 [online]. Department for Transport, London. Available from:

https://www.gov.uk/government/uploads/system/uploads/attachment data/file/664323/tsgb2017-print-ready-version.pdf [Accessed 26 March 2018].

Faulconbridge, J. and Hui, A. (2016) 'Traces of a Mobile Field: Ten Years of Mobilities Research' Mobilities, 11(1): pp.1-14.

Fincham, B., McGuiness, M. and Murray, L. (eds) (2010) Mobile Methodologies, Palgrave Macmillan, Basingstoke.

Finlay, J.M. and Bowman, J.A. (2017) 'Geographies on the Move: A Practical and Theoretical Approach to the Mobile Interview' The Professional Geographer, 69(2): pp.263-274.

Hannam, K., Sheller, M. and Urry, J. (2006) 'Editorial: Mobilities, Immobilities and Moorings' Mobilities, 1(1): pp.1-22.

Harada, T. and Waitt, G. (2013) 'Researching Transport Choices: The Possibilities of 'Mobile Methodologies' to Study Life-on-the-Move' Geographical Research, 51(2): pp.145-152.

Kitchin, R. and Dodge, M. (2011) Code/Space: Software and Everyday Life, The MIT Press, London.

Kusenbach, M. (2003) 'Street Phenomenology: The Go-Along as Ethnographic Research Tool' Ethnography, 4: pp.455-85.

Kwan, M.P. and Schwanen, T. (2016) 'Geographies of Mobility' Annals of the American Association of Geographers, 106(2): pp.243-256

Larsen, J. (2014) '(Auto)Ethnography and cycling' International Journal of Social Research Methodology, 17(1): pp.59-71

Lavau, S. (2014) 'Viruses' in: Adey, P., Bissell, D., Hannam, K., Merriman, P. and Sheller, M. (eds) The Routledge Handbook of Mobilities, Routledge, Abingdon: pp.298-305.

Law, J. (2006) 'Disaster in agriculture: or foot and mouth mobilities' Environment and Planning A, 38(2): pp.227-239.

Lin, W. (2015) 'Cabin pressure': designing affective atmospheres in airline travel' Transaction of the Institute of British Geographers, 40(2): pp.287-299.

Lumsden, K. (2013) Boy Racer Culture: Youth, Masculinity and Deviance, Routledge, Abingdon.

Massey, D. (1993) 'Power-geometry and a progressive sense of place' in: Bird, J., Curtis, B., Putnam, T., Robertson, G. and Tickner, L. (eds) Mapping the Futures: Local Cultures, Global Change, Routledge, London: pp.60-70.

Massey, D. (2005) For Space, Sage, London. 
Merchant, S. (2017) 'The promise of creative/participatory mapping practices for sport and leisure research' Leisure Studies, 36(2): pp.182-191.

Merriman, P. (2009) 'Automobility and the Geographies of the Car' Geography Compass, 3(3): pp.586-599.

Merriman, P. (2014) 'Rethinking Mobile Methods' Mobilities, 9(2): pp.167-187.

Merriman, P. (2015) 'Mobilities I: Departures' Progress in Human Geography, 39(1), 87-95.

Merriman, P. (2016) 'Mobilities II: Cruising' Progress in Human Geography, 40 (4), pp. 555-564.

Merriman, P. (2017) 'Mobilities III: Arrivals' Progress in Human Geography, 41(3): pp.375-381.

Merriman, P., Peters, K., Adey, P., Cresswell, T., Forsyth, T. and Woodward, R. (2017) 'Interventions on military mobilities' Political Geography, 56: pp.44-52.

Middleton, J. (2010) 'Sense and the city: exploring the embodied geographies of urban walking' Social \& Cultural Geography, 11(6): pp.575-596.

Murray, L. and Upstone, S. (eds) (2014) Researching and Representing Mobilities: Transdisciplinary Encounters, Palgrave Macmillan, Basingstoke.

Novoa, A. (2015) 'Mobile ethnography: emergence, techniques and its importance to geography' Human Geographies - Journal of Studies and Research in Human Geography, 9(1): pp.97-107.

Ricketts Hein, J., Evans, J. and Jones, P. (2008) 'Mobile Methodologies: Theory, Technology and Practice' Geography Compass, 2(5): pp.1266-1285.

Shaw, J. and Hesse, M. (2010) 'Transport, geography and the "new" mobilities' Transactions of the Institute of British Geographers, 35(3): pp.305-312.

Shaw, J. and Sidaway, J.D. (2011) 'Making links: On (re)engaging with transport and transport geography' Progress in Human Geography, 35(4): pp.502-520.

Shaw, J. and Docherty, I. (2014) 'Geography and Transport' in: Adey, P., Bissell, D., Hannam, K., Merriman, P. and Sheller, M. (eds) The Routledge Handbook of Mobilities, Routledge, Abingdon: pp.25-36.

Sheller, M. (2011) Mobility [online]. Sociopedia, International Sociological Association, London. Available at: http://www.sagepub.net/isa/resources/pdf/mobility.pdf [Accessed 26 March 2018].

Sheller, M. (2017) 'From spatial turn to mobilities turn' Contemporary Sociology, 65(4): pp.623-639.

Sheller, M. and Urry, J. (2006) 'The new mobilities paradigm' Environment and Planning A, 38(2): pp.207-226.

Sheller, M. and Urry, J. (2016) 'Mobilizing the new mobilities paradigm' Applied Mobilities, 1(1): pp.10-25.

Simpson, P. (2014) 'Video' in: Adey, P., Bissell, D., Hannam, K., Merriman, P. and Sheller, M. (eds) The Routledge Handbook of Mobilities, Routledge, Abingdon: pp.542-552.

Spence, E. (2014) 'Unraveling the Politics of Super-rich Mobility: A Study of Crew and Guest on Board Luxury Yachts' Mobilities, 9(3): pp.401-413. 
Spinney, J. (2009) 'Cycling the City: Movement, Meaning and Method' Geography Compass, 3(2): pp.817-835.

Spinney, J. (2011) 'A Chance to Catch a Breath: Using Mobile Video Ethnography in Cycling Research' Mobilities, 6(2): pp.161-182.

Spinney, J. (2015) 'Close encounters? Mobile methods, (post)phenomenology and affect' Cultural Geographies, 22(2): pp. 231-246.

Temenos, C. and McCann, E. (2013) 'Geographies of policy mobilities' Geography Compass, 7(5): pp.344-357.

Taylor, L. (2016) 'No place to hide? The ethics and analytics of tracking mobility using mobile phone data' Environment and Planning D: Society and Space, 34(2): pp.319-336.

Vannini, P. (2010) 'Mobile Cultures: From the Sociology of Transportation to the Study of Mobilities' Sociology Compass, 4(2): pp.111-121.

Watts, L. and Urry, J. (2008) 'Moving Methods, Travelling Times' Environment and Planning D: Society and Space, 26(5): pp.860-874.

Urry, J. (2007) Mobilities, Polity, Cambridge. 